\title{
Caracterização da silagem de milho, produzida em propriedades rurais do sudoeste do Paraná
}

\author{
Valmir da Cunha Vieira'; Valério Moro² ; Dione Farinacio² ${ }^{2}$ Thomas Newton Martin ${ }^{3 *}$ \\ Luis Fernando Glasenapp de Menezes ${ }^{4}$
}

\begin{abstract}
RESUMO
O objetivo deste trabalho foi caracterizar a produção e utilização da silagem, nos sistemas produtivos, em propriedades leiteiras do sudoeste do Paraná. A coleta dos dados foi realizada de março a maio de 2009, em propriedades produtoras de leite, em sete municípios paranaenses, totalizando 108 propriedades visitadas. O questionário, de caráter qualiquantitativo, compreendia 28 questões pré-definidas. A produção leiteira pode ser ampliada pela utilização de técnicas de manejo, como a escolha correta do híbrido e o planejamento e escalonamento adequado da semeadura. A região sudoeste do Paraná caracteriza-se por apresentar pequenas propriedades rurais (agricultura familiar), com 15,65 vacas em lactação e 17,2 litros de leite/dia, em média, e que armazenam a silagem em silos trincheira, em sua maioria. As lavouras cultivadas para confecção de silagem produzem em média 40 a 50 ton ha-1 de matéria verde. Além disso, os principais híbridos utilizados para a confecção da silagem são do grupo semi-duro e precoce, com sementes certificadas e tratadas.
\end{abstract}

Palavras-chave: Silagem, atividade leiteira, propriedades leiteiras, Zea mayz L.

\section{ABSTRACT}

\section{Characterization of corn silage produced in farms of Southwest Paraná State, Brazil}

The objective of this work was to characterize the production and utilization of corn silage in milk farms in Paraná State, Brazil. Data was collected from March to May, 2009, in seven municipalities, comprising 108 farms visited. A quali-quantitative questionnaire consisting of 28 predefined questions was applied to farmers. Milk production can be increased by adopting management techniques such as the correct hybrid choice, planning and right sowing scheduling. The southwestern region of the Paraná is characterized by small farms, with 15.65 cows in lactation and 17.2 liters of milk/day, on average, and the silage is stored mainly in trench silos. The cultivated areas for silage produce 40 to 50 ton $\mathrm{ha}^{-1}$ on average of fresh matter.The main corn hybrids used for silage belong to the semi-hard and early group, with certified and treated seeds.

Key words: silage, milk activity, milk farm, Zea mayz L.

Recebido para publicação em 09/06/2010 e aprovado em 28/06/2011

${ }^{1}$ Médico Veterinário. Programa de pós-graduação em Agronomia, Universidade Tecnológica Federal do Paraná, Estrada para Boa Esperança, Dois Vizinhos, 85660-000, C. P. 157, Paraná, Brasil.valmir_nutre@ hotmail.com

${ }^{2}$ Engenheiro-Agrônomo. Programa de pós-graduação em Agronomia, Universidade Tecnológica Federal do Paraná, Estrada para Boa Esperança, Dois Vizinhos, 85660-000, C. P. 157, Paraná, Brasil.valeriomoro@bol.com.br, dionefarinacio@hotmail.com

${ }^{3}$ Engenheiro-Agrônomo, Doutor. Unversidade Federal Federal de Santa Maria, Centro de Ciências Rurais, Departamento de Fitotecnia, Av. Roraima, n. 1000, Camobi, 97105-900, Santa Maria, RS, Brasil. martin.usm@gmail.com *Autor para correspondência.

4 Zootecnista, Doutor. Universidade Tecnológica Federal do Paraná, Estrada para Boa Esperança, Dois Vizinhos, 85660-000, C. P. 157, Paraná, Brasil. luismenezes@utfpr.edu.br 


\section{INTRODUÇÃO}

Para que as ações políticas e extensionistas possam ser aplicadas aos produtores rurais, é necessário, primeiramente, entender as cadeias produtivas e, a partir daí, traçar estratégias que melhorem a situação da cadeia produtiva em questão. Estratégias como a aplicação de questionários e visitas técnicas às propriedades rurais podem ser utilizadas para caracterizar determinado setor produtivo e realizar inferências. Com esse objetivo, Bressan et al. (2009) avaliaram 81 questionários, respondidos por prefeitos de municípios rurais de pequeno porte no Estado de Minas Gerais, podendo, assim, realizar inferência para o planejamento agropecuário. Muitas vezes esse é um processo de longo prazo e que precisa ser otimizado para agilizar a tomada de decisão.

O Estado do Paraná vem apresentando um expressivo crescimento da produção leiteira, obtendo um crescimento de $71 \%$ no período entre 1997 até 2006, consolidandose como terceiro estado produtor de leite do Brasil, com uma produção de 2,7 bilhões de litros. No Brasil, houve um crescimento, nesse mesmo período, de $12,4 \%$ na produção, ultrapassando os 20 bilhões de litros (IBGE, 2006). Somente os Estados do Rio Grande do Sul e de Minas Gerais, com produções de 2,94 bilhões e 7,27 bilhões de litros, respectivamente, superam a produção paranaense.

No Paraná, a expansão da produção de leite foi mais intensa nas regiões oeste e sudoeste, com forte crescimento do rebanho e dos níveis de produtividade (IPARDES, 2009). A região sudoeste do Paraná, de acordo com dados do Instituto Brasileiro de Geografia e Estatística (IBGE, 2008), possui 27.355 mil estabelecimentos agropecuários, dos quais $61,3 \%$ do total exploram de forma econômica a atividade leiteira, sendo a segunda maior produtora do Estado, e a região oeste a detentora da maior produção. Dados preliminares do Censo Agropecuário (IBGE, 2008) apontam uma redução no número de propriedades leiteiras, na região sudoeste, de 47.277 (1996) para 44.632 (2006), ou seja, uma variação de 5,59\%. Entretanto, houve aumento na produção de litros de leite, por estabelecimento, de 4.633 litros (1996) para 13.905 litros (2006) por mês, uma variação de $200 \%$ por estabelecimento.

A produção de forragem para alimentação dos rebanhos leiteiros e de corte, na região sudoeste do Paraná, apresenta períodos de estacionalidade que comprometem a disponibilidade de volumosos em quantidade e qualidade. Além disso, Valle et al. (2009) indicam que são poucos os gêneros e as espécies, trabalhadas com a finalidade de melhoramento genético, que podem atender à demanda de extensas áreas. Contribuindo com isso, a ocorrência de vazio forrageiro outonal e, ou, primaveril interfere na produção de leite e corte da região (Pasciullo et al., 2008).
Durante o período seco do ano, as pastagens tornamse deficientes, sendo necessário o uso de uma fonte adicional de volumoso. Nesse período, as pastagens perdem seu valor nutritivo, reduzem sua produção de massa verde e aumentam seus valores de fibra detergente neutra (FDN), o que reduz o seu consumo em percentagem de peso vivo pelos animais (Mello \& Pedreira, 2004).

O milho é, cada vez mais, recomendado entre as várias plantas aptas à produção de silagem (sorgo, girassol, aveia, azevém, milheto, etc), sendo a cultura de maior expressão no Brasil (Oliveira et al., 2007a). Assim, a silagem de milho continua sendo uma das melhores opções de suplementação, nesse período, por apresentar uma produção elevada de massa por unidade de área, alto rendimento de massa verde por hectare, boa qualidade, facilidade de fermentação no silo, além de boa aceitação por parte dos bovinos e ganhos de pesos satisfatórios em confinamentos (Restle $e t$ al., 2006), sendo um alimento de alta qualidade para os animais (Pimentel et al., 1998). A adoção da ensilagem, como forma de conservação da forragem, é uma alternativa cada vez mais empregada, como estratégia alimentar para o período de escassez, maximização do uso da terra e melhoria na rentabilidade do sistema produtivo (Oliveira et al., 2007a). Silagens de elevado potencial para desempenho animal são obtidas de híbridos de milho, selecionados por características que confiram elevada concentração de energia na massa das plantas, estabilidade de índices de produtividade e de produção de grãos (Neumann et al., 2001). O planejamento estratégico do sistema de produção baseia-se em informações relacionadas com a projeção de crescimento do rebanho, com a identificação de épocas críticas para sua nutrição (estação de monta, recria, engorda, dentre outras) e com o estabelecimento de níveis projetados de produtividade das pastagens ao longo do ano (Barioni et al., 2003).

Dessa forma, o objetivo proposto para este trabalho foi o de caracterizar a produção e utilização da silagem nos sistemas produtivos em propriedades leiteiras do sudoeste do Paraná.

\section{MATERIAL E MÉTODOS}

O presente estudo foi realizado nos municípios de Laranjeiras do Sul, Espigão Alto do Iguaçu, São João, São Jorge D'Oeste, Coronel Vivida, Verê e Itapejara D'Oeste, pertencentes à região sudoeste do Paraná, totalizando 108 questionários aplicados diretamente aos produtores de leite que se utilizam de silagem para a alimentação dos animais. A área territorial abrangida pelo levantamento equivale a $3014 \mathrm{~km}^{2}$ e o clima é classificado como Cfa (Clima Subtropical Úmido (Mesotérmico)), com média do mês mais quente superior a $22^{\circ} \mathrm{C}$ e, no mês mais frio, inferior a $18^{\circ} \mathrm{C}$, sem estação seca definida, verão quente e geadas menos frequentes), segundo a classificação de Köppen (Maark, 1968).

Rev. Ceres, Viçosa, v. 58, n.4, p. 462-469, jul/ago, 2011 
Utilizou-se a amostragem aleatória para seleção dos produtores entrevistados, não se levando em conta gênero, idade, grau de instrução, renda ou tamanho da propriedade rural. As entrevistas foram realizadas em eventos regionais, escritórios de assistência técnica e extensão rural e visitas a propriedades rurais. Anteriormente à aplicação do questionário, foi explanada a importância da pesquisa, bem como seus objetivos, de modo a sensibilizar os produtores para o fornecimento de informações corretas.

A aplicação do questionário teve o intuito de identificar as condições das propriedades, em relação à área útil da propriedade e a área utilizada para produção de silagem, escolha de híbridos, manejo e tratos culturais utilizados. As questões abordadas no questionário relacionaram-se à: área útil da propriedade; área de silagem/ano; grupo de milho (duro, semiduro ou dentado, ou não sabe); nome comercial do genótipo utilizado para silagem; origem da semente; ciclo do genótipo utilizado (Hiperprecoce, superprecoce, precoce, normal ou não sabe); cultura antecessora (aveia, milho, soja, trigo, feijão, campo nativo, fumo, aveia de verão, não realizou); tratamento de sementes; operação de semeadura (própria ou contratada); sistema de semeadura (direto, convencional ou cultivo mínimo); espaçamento entre fileiras; número de plantas por metro linear; população estimada de plantas; controle de plantas daninhas; controle de pragas; principal praga; adubação nitrogenada; afiação de facas e contrafaca no dia da ensilagem; tipo de silo (trincheira ou superfície); tamanho estimado do silo $\left(\mathrm{m}^{3}\right)$; período de uso da silagem; análise químico-bromatológica da silagem; teor de matéria seca; processo de compactação (horizontal ou com inclinação); verificação de perdas de silagem; produtividade da silagem; composição do rebanho (vacas em lactação, vacas secas, novilhas de menos de um ano, novilhas entre 12 e 24 meses) e produção média de leite/vaca/dia.

A partir dos dados obtidos, foi gerado um banco de dados e foram realizadas as análises estatísticas de posição (média, mínimo e máximo) e mediana. As estatísticas de dispersão estimadas foram o erro padrão da média, desvio padrão, curtose e assimetria, e nível de confiança para a média (95\%). Posteriormente, aplicou-se o teste de correlação de Pearson nas variáveis selecionadas. As análises foram realizadas com o auxílio do software Microsoft Excel ${ }^{\circledR}$.

\section{RESULTADOS E DISCUSSÃO}

Segundo os dados apresentados na Tabela 1, os agricultores entrevistados possuíam, em média, área útil da propriedade de 22,85 ha (de 2,5 ha até 227,48 ha), sendo que, em média, 16,1\% foram destinadas à silagem. Esse valor está dentro da realidade regional de agricultura fa- miliar, em que, aproximadamente, $92,7 \%$ dos estabelecimentos rurais da região sudoeste Paranaense possuem até 50 ha (IBGE, 2008).

Em relação à população de plantas ha-1, a média foi de 62.030, sendo um parâmetro adequado conforme as recomendações das empresas sementeiras, para os híbridos, de forma a obter produtividades em torno de 40 a 50 ton ha ${ }^{-1}$ de matéria verde (Piana et al., 2008). Em relação ao grupo de milho, houve predominância do grupo semiduro, com a participação de 50,93\%; os demais grupos, dentado e duro, obtiveram $10,19 \%$ e $16,67 \%$, respectivamente. Esses dados demonstram que o produtor da região pode estar perdendo em produtividade animal, uma vez que os milhos do grupo dentado apresentam maior degradação ruminal e menor proporção entre endosperma duro e endosperma total (vitreosidade), quando comparados com os grupos duros (Corrêa et al., 2003). Os mesmos autores consideram importante o estudo e entendimento da influência da textura do grão sobre o desempenho das vacas leiteiras no Brasil, salientando que os milhos para silagem nos Estados Unidos são todos do grupo dentado. Corrêa et al. (2002), avaliando 40 híbridos de milho dentado americanos e cinco híbridos brasileiros, cultivados em seus respectivos países, observaram que os milhos de textura dura (Flint) apresentaram menor disponibilidade de amido (Pereira et al., 2004). Os grupos de milhos utilizados para silagem têm importância, não somente quanto à produtividade de cada material, mas também pelo efeito direto no desempenho animal, fator determinante no sistema de produção de leite (Phillipeau et al., 1999; Corrêa et al., 2002).

Segundo Oliveira et al. (2007a), apesar da importância da qualidade da forragem fornecida aos animais, são incomuns resultados de pesquisa referentes à avaliação da qualidade da silagem de diferentes híbridos de milho, podendo ser melhorado o conhecimento nessa área. Considerando-se os aspectos anteriormente discutidos, os milhos do grupo dentado apresentam maior digestibilidade ruminal do amido que os milhos do grupo semiduro e duro, sendo, no entanto, menos disponibilizados aos produtores pelo mercado de sementes de milho para silagem (Corrêa et al., 2002; Rossi Junior et al., 2006).

Foi encontrada uma grande diversidade de híbridos, sendo os mais representativos os híbridos: AG 2040 (18,40\%); AG 5011 (12,00\%); AS 32 (8,00\%); 30P34 (7,20\%) e AS $1570(6,40 \%)$ que representam 52\% da área semeada na região pesquisada (total de 28 genótipos citados). Porém, é relevante o percentual de produtores que cultivam milho para ensilagem, mas não sabem informar o nome comercial utilizado $(14,81 \%)$. Além disso, 22,22\% dos participantes do questionário desconhecem o tipo de milho que estão cultivando e se este atende à especificação para produção de silagem. 
Verifica-se que os híbridos mais semeados têm como finalidade a ensilagem, conforme recomendações das próprias empresas. Os híbridos disponíveis no mercado apresentam forte interação genótipo $\mathrm{x}$ ambiente, sendo necessárias avaliações em vários locais, para a identificação daqueles com melhor desempenho em regiões específicas (Oliveira et al., 2003; Oliveira et al., 2007b).

Embora a seleção de híbridos para produção de grãos de milho seja baseada em produção de grãos e de matéria seca total, para a avaliação do potencial para silagem, outros componentes da planta, como sabugo, colmo, folhas, palhas e qualidade bromatológica, não têm sido devidamente avaliados. Deste modo, pode existir uma considerável variabilidade entre híbridos de milho, mesmo estes recebendo o mesmo tratamento, já que nem sempre a maior produção confere uma melhor qualidade de silagem (Queiroz et al., 2000).

Os produtores buscam, cada vez mais, adquirir sementes certificadas, testadas e comprovadas geneticamente quanto às características de alta qualidade, alta produção e grãos de qualidade desejável, com a ressalva de que se orientam apenas pelas recomendações das empresas que comercializam as sementes e não por informações de pesquisa sobre o desempenho dos híbridos. Com isso, observou-se que a maioria dos produtores $(95,37 \%)$ adquire sementes certificadas em agropecuárias. Segundo Kikut et al. (2003), a qualidade das sementes influencia a veloci- dade de estabelecimento da cultura e a uniformidade do estande, afetando assim a produção. Com relação ao tratamento de sementes, foi constatado que $90,74 \%$ dos agricultores realizam essa prática, bem como 90,15 e 90,74\% realizam o controle de plantas daninhas e pragas, respectivamente.

Os grupos de milho diferenciam-se segundo o número de graus dias acumulados até o florescimento, sendo eles: superprecoces (são necessários 780-830 GD), precoces (831-890 GD), e normais (890-1200 GD) (Gadioli et al., 2000; Sangoi et al., 2002). No entanto, observou-se que o grupo precoce é o mais representativo, com $52,78 \%$ dos genótipos utilizados. Porém, Flaresso et al. (2000) estudaram cultivares de milho para a produção de silagem e verificaram que, nos ciclos mais tardios, a altura da planta foi maior, em comparação com a dos ciclos precoces, enquanto o número de espigas por plantas foi igual a um, em ambos os casos.

A maioria dos agricultores entrevistados utiliza como cultura antecessora a aveia $(35,19 \%)$, o próprio milho (no caso do milho safrinha, $28,70 \%)$ e a soja $(24,07 \%)$; em função disso, mais da metade dos produtores produz silagem na safrinha do milho (Tabela 2). A utilização da aveia como cultura antecessora ao milho pode gerar problemas em relação às características químicas, físicas e biológicas do solo, pela redução da disponibilidade nitrogênio, dentre outros (Argenta et al., 2001). Segundo

Tabela 1. Estatística descritiva para as variáveis área útil da propriedade (AU, ha), área semeada com milho para silagem (AMS, ha), espaçamento entre plantas (EP, cm), número de plantas por metro linear (NP), população de plantas (POP, x 1000), quantidade de uréia, aplicada por hectare (DU, $\mathrm{kg} \mathrm{ha}^{-1}$ ), dose de sulfato de amônio (DSA, $\mathrm{kg} \mathrm{ha}^{-1}$ ), tamanho do silo (TS, $\mathrm{m}^{-3}$ ), produção de silagem $\left(\mathrm{PS}, \mathrm{m}^{-3}\right.$ ), número de vacas em lactação (VL), número de vacas secas (VS), número de novilhas de 12 a 24 meses (NOV), novilhas com menos de um ano (NUA), produção de leite por vaca por dia (PL)

\begin{tabular}{|c|c|c|c|c|c|c|c|}
\hline Estatísticas & $\mathbf{A U}$ & AMS & EP & NP & POP & DU & DSA \\
\hline Média & 22,96 & 3,88 & 0,81 & 5,11 & 62,04 & 241,81 & 150,00 \\
\hline $\mathrm{EP} *$ & 2,58 & 0,32 & 0,01 & 0,07 & 1,06 & 7,41 & 0,00 \\
\hline Mediana & 16,33 & 2,42 & 0,80 & 5,00 & 60,00 & 250,00 & 150,00 \\
\hline $\mathrm{DP} * *$ & 27,07 & 3,36 & 0,08 & 0,74 & 11,09 & 77,00 & \\
\hline Curtose & 31,94 & 3,43 & 10,98 & 0,05 & 1,56 & 0,38 & \\
\hline Assimetria & 5,00 & 1,85 & $-2,47$ & 0,69 & 1,10 & $-0,95$ & \\
\hline Mínimo & 2,50 & 0,50 & 0,40 & 4,00 & 44,44 & 0,00 & 150,00 \\
\hline Máximo & 227,48 & 16,94 & 0,90 & 7,00 & 100,00 & 372,00 & 150,00 \\
\hline $\mathrm{NC} * * *$ & 5,12 & 0,63 & 0,01 & 0,14 & 2,09 & 14,69 & \\
\hline Estatísticas & TS & PS & VL & VS & NOV & NUA & PL \\
\hline Média & 190,62 & 43,38 & 15,65 & 3,72 & 5,98 & 5,48 & 17,20 \\
\hline $\mathrm{EP}$ & 13,24 & 0,96 & 0,78 & 0,21 & 0,29 & 0,33 & 0,49 \\
\hline Mediana & 164,00 & 43,00 & 14,00 & 3,00 & 5,00 & 5,00 & 17,00 \\
\hline $\mathrm{DP}$ & 137,61 & 9,91 & 8,11 & 2,20 & 3,00 & 3,39 & 5,14 \\
\hline Curtose & 1,88 & 1,69 & 3,67 & 2,69 & 0,28 & 1,24 & $-0,39$ \\
\hline Assimetria & 1,34 & 0,80 & 1,79 & 1,38 & 0,71 & 1,03 & 0,08 \\
\hline Mínimo & 1,00 & 24,79 & 5,00 & 0,00 & 0,00 & 0,00 & 5,00 \\
\hline Máximo & 680,00 & 80,00 & 46,00 & 12,00 & 14,00 & 18,00 & 29,70 \\
\hline $\mathrm{NC}$ & 26,25 & 1,90 & 1,55 & 0,42 & 0,57 & 0,65 & 0,98 \\
\hline
\end{tabular}

*EP = erro padrão; ** DP = desvio padrão; *** NC = nível de confiança para média $(\mathrm{NC}, 95 \%)$. 
Maeda et al. (1997), a utilização de rotação de culturas com espécies capazes de realizar simbiose com micro-organismos, fixar nitrogênio $(\mathrm{N})$, ou espécies com grande capacidade de reciclar nutrientes, permite reduzir sua necessidade de $\mathrm{N}$ aplicado na cultura do milho, fato que não está acontecendo na região pesquisada. Apesar da crescente utilização da silagem de milho como alimento volumoso, verifica-se a utilização de conceitos equivocados na escolha de híbridos, nos manejos culturais e no processo de ensilagem, em que a qualidade do produto final não é priorizada (Dias, 2002).

Quanto à análise químico-bromatológica, o percentual de produtores que realizam essa prática não atinge 10\%, o que indica que $90 \%$ não possuem o conhecimento dessa prática, nem os benefícios do conhecimento que os resultados podem trazer ao planejamento alimentar. Segundo Keplin (1992), uma silagem, para ser considerada de boa qualidade, deve apresentar de 7,1 a $8 \%$ de proteína bruta (PB) e 64 a 70\% de NDT. No entanto, há muita variação entre cultivares. Flaresso et al. (2000), estudando vários híbridos de milho para produção de silagem, observaram PB variando de 7,2 a 8,8\% e NDT de 50,4 a 61,8\%.

Segundo Silva et al. (2002), um dos fatores que comprometem o rendimento e a qualidade da produção do milho destinado à ensilagem é a interferência exercida pelas plantas daninhas. Dentre os fatores que influenciam a interferência, destaca-se o período em que a população de plantas daninhas está competindo com a cultura pelos recursos do ambiente. O controle de pragas é realizado por $90 \%$ dos produtores, dentre elas a principal é a lagarta-do-cartucho (Spodoptera frugiperda), ocorrendo em $87,96 \%$ das propriedades. Segundo Viana et al. (2001), o ataque da lagarta-do-cartucho no início de desenvolvimento da cultura acarreta redução do número de plantas na área, pois a plântula fatalmente será morta pelo ataque das lagartas, podendo causar prejuízos que variam em média de 18,7 a 37,7\%. Há também ocorrência de 10,19\% de lagarta elasmo (Elasmopalpus lignosellus) e um ataque de apenas $1,85 \%$ da broca do colmo (Diatraea saccharalis).

Constatou-se que, como fonte de adubação nitrogenada (mineral), a ureia é a principal (quase 100\%), com dose mínima de $55 \mathrm{~kg} \mathrm{ha}^{-1}$, média de $244 \mathrm{~kg} \mathrm{ha}^{-1}$ e máxima de 372 $\mathrm{kg} \mathrm{ha}^{-1}$. Em alguns casos, houve redução da dosagem de ureia, mas complementada com outras fontes de nitrogênio, como o sulfato de amônio e estercos.

Em um estudo semelhante, realizado em dois anos no sudoeste do Paraná, com 305 produtores de milho para grãos, verificou-se que a maioria dos agricultores (89\%) utilizou adubação nitrogenada na cultura, o que favorece um maior aproveitamento da cultura e maior produtividade (Martin et al., 2011). Os mesmos autores ainda observaram os mais variados tipos de adubações nitrogenadas, destacando-se, porém, a ureia (64,7 e 63,6\% em 2007 e 2008 , respectivamente), na forma de esterco de aves (20,3 e $25,3 \%$, em 2007 e 2008, respectivamente) e nas demais formas encontradas, como esterco de suínos, sulfato de amônio e adubo químico (15 e 11,9\%, em 2007 e 2008, respectivamente). Outros estudos (Martin et al., 2011a) apresentam as funções dos principais macronutrientes, indicando que o nitrogênio é um dos elementos mais utilizados para desenvolvimento da cultura. Para a produção de silagem, alguns autores apresentam a extração de nitrogênio (Martin et al., 2010), que pode chegar a expor$\operatorname{tar} 413 \mathrm{~kg}$ de nitrogênio ha-1, para produções de cerca de 19 toneladas de silagem por hectare.

A prática de afiação de facas e contrafacas é realizada, duas vezes ao dia, por quase metade dos agricultores $(48,15 \%)$, contribuindo em parte para a obtenção de tamanho de partículas mais uniformes, que favorecem a compactação, e, esta, o processo de fermentação, pela retirada do oxigênio. Dessa forma, situações em que a redução do tamanho médio da partícula é limitada pela eficiência das colhedoras de forragem tornam-se o principal fator restritivo ao aumento da densidade da silagem (Balsalobre et al., 2001).

Quanto ao modo de estocagem da silagem, existem vários tipos de silos, que atendem à necessidade no que se refere ao volume estocado e a diferentes topografias para sua construção e localização (Oliveira \& Martins, 2009). O silo trincheira é o tipo mais utilizado pelos produtores $(84,26 \%)$, comparado com o silo em superfície $(15,74 \%)$, por diversas vantagens, como: baixo custo de construção e facilidades de carregamento, compactação e descarregamento (Oliveira \& Martins, 2009). De acordo com Vilela et al. (1998), trabalhando com a produção de silagem e armazenamento em silos tipo superfície e trincheira, foram encontradas perdas de 41,5 e 28,0\%, respectivamente, durante o processo de produção e utilização de silagem (etapas de colheita, armazenamento e alimentação dos animais), o que, segundo o autor, eleva o custo

Tabela 2. Número de produtores (NP) e percentual (\%) referente à cultura antecessora ao milho utilizado para silagem em propriedades leiteiras no sudoeste do Paraná

\begin{tabular}{lcr}
\hline Cultura antecessora & NP & $(\boldsymbol{\%})$ \\
\hline Aveia & 38 & 35,19 \\
Milho & 31 & 28,70 \\
Soja & 26 & 24,07 \\
Feijão & 9 & 8,33 \\
Trigo & 1 & 0,93 \\
Campo nativo & 1 & 0,93 \\
Não cultivou & 1 & 0,93 \\
Aveia de verão & 1 & 0,93 \\
Fumo & 0 & 0,00 \\
\hline Total & 108 & 100 \\
\hline
\end{tabular}


de produção da silagem. O revestimento com lona é o mais utilizado $(65,74 \%)$, para proteção e conservação da silagem. Porém, apenas $4,63 \%$ dos produtores têm seus silos revestidos com alvenaria e um percentual expressivo $(29,63 \%)$ dos produtores entrevistados não reveste os silos, possivelmente por falta de conhecimento dos benefícios do revestimento dos silos.

É expressivo o percentual de produtores que fazem silagem para a utilização durante o ano todo, chegando a quase $55 \%$. A prática encarece o processo de produção; entretanto, permite maior estabilidade das dietas fornecidas aos rebanhos. A produção de silagem apenas para os períodos críticos ou somente para utilização durante o inverno foi de 15,74 e 29,63\%, respectivamente. De acordo com Holmes (1996), a produção de leite a pasto é o sistema com menor custo por quilo de matéria seca, sendo a fonte de nutriente mais econômica em qualquer parte do mundo.

A forma de compactação mais utilizada para a silagem foi por inclinação, sendo importante para a retirada do oxigênio e para garantir condições anaeróbias para preservação dos nutrientes (Johnson et al., 2002). Porém, a quantificação exata das perdas depende da coleta de amostras que representem a condição de armazenamento (Bolsen, 1996). A densidade e o teor de matéria seca determinam a porosidade da silagem, a qual estabelece a taxa de aeração e, posteriormente, o grau de deterioração na armazenagem e na desensilagem (Bolsen \& Bolsen, 2004). Foi verificado que as maiores perdas de silagem ocorrem no silo $(68,52 \%)$, tendo as perdas de cocho e na colheita apresentado valores significativos de 18,52 e 12,96\%, respectivamente. As perdas são variáveis, dependendo do tipo de silo, da presença ou não de revestimento, do processo de ensilagem e do momento da ensilagem. É recomendável não retirar camadas inferiores a $15 \mathrm{~cm}$, pois isso ocasiona perdas de $11 \%$ de matéria seca, por deterioração aeróbica pela exposição do material ao oxigênio.

Nas categorias de rebanho, as propriedades rurais entrevistadas possuem em média 15,65 vacas em lactação, com total de 30,83 animais. Nas categorias de menor idade, foi observado que o número de novilhas para reposição, com menos de um ano até dois anos de idade, é de 33,87\%. Segundo Santos et al. (2001), o índice zootécnico para novilhas é de 15 a $20 \%$ da atividade leiteira; no entanto, índices acima desses valores podem onerar os custos ou diminuí-los, caso se consiga baixar a idade ao primeiro parto e, assim, dispor de novilhas para comercialização. Porém, isso é justificável, na região, a prática de retenção de fêmeas com a finalidade de expansão da atividade leiteira e isso vai ao encontro do crescimento da atividade na região sudoeste do Paraná. A percentagem de vacas em lactação é de 80,79\%, índice zootécnico considerado adequado para atividade leiteira, o qual repre- senta o manejo ajustado dos plantéis entrevistados, sendo que os dados encontrados concordam com os relatados por Santos et al. (2001).

A maioria dos produtores $(69,44 \%)$ utiliza a raça Holandesa, o que pode ser explicado pela alta produção de leite dessa raça, quando recebe manejo adequado. Os percentuais encontrados nessa pesquisa para raças bovinas estão de acordo com os dados do IPARDES (2009). No Paraná, pouco mais da metade dos rebanhos bovinos dispõe de animais com características da raça Holandesa e 40\% deles têm animais da raça Jersey. Entre os produtores com maior número de animais, a raça Holandesa representa $2 / 3$ do rebanho.

A produção de leite por vaca ficou em média de 17,2 litros, a mínima de 5 litros e a máxima de 29,7 litros, sendo os dados obtidos superiores a produtividade média Paranaense, que é de 5,5 litros/vaca/dia, e também superior a média nacional, que é de 4,37 litros/vaca/dia (IBGE, 2008), média considerada baixa, quando comparada com os principais países produtores (SEAB/DERAL, 2003).

Na Tabela 3, estão apresentadas as correlações entre as variáveis (somente os valores superiores a $|0,50|$ ). Apesar da correlação de Pearson ser aplicada para todas as variáveis, alguns pares de variáveis não possuem relação causa e efeito; dessa forma, a respeito dessas não serão realizadas inferências. Verifica-se que existe uma relação entre o tamanho da propriedade e o número de novilhas abaixo de um ano $(0,53)$. Portanto, quanto maior o tamanho da área cultivada com milho para silagem, maior é o tamanho do silo $(0,59)$ e quanto maior o silo, maior é o período de utilização da silagem (ano todo) $(0,59)$, bem como o número de vacas em lactação $(0,63)$ e o número de novilhas menores de um ano $(0,53)$. No que diz respeito ao ciclo dos cultivares, quanto mais precoce é o ciclo da cultura mais os agricultores utilizam esterco de aves $(0,85)$. A utilização de inseticidas é realizada para controlar principalmente a lagarta do cartucho $(0,85)$. Os agricultores que possuem grande produção de silagem (grandes silos) são os que menos utilizam esterco de aves $(-0,91)$. As propriedades que apresentam grande produção de silagem tendem a ser mais especializadas e as que possuem maior produtividade por animal/dia $(0,59)$. O número de vacas em lactação está intimamente correlacionado com o número de vacas secas $(0,60)$, novilhas até um ano $(0,74)$ e novilhas acima de um ano $(0,74)$. Além disso, as maiores produtividades de leite ocorrem em propriedades que possuem maiores plantéis da raça holandesa $(0,53)$. Quanto à correlação entre a área útil de milho utilizado para a produção de silagem e a produção de leite, essa foi de 0,44 . Porém, ao considerar-se a área cultivada para silagem e a produção total de leite da propriedade, a correlação é de 0,64 . Nesse caso, a correlação não é maior pelo fato de a silagem fazer parte da dieta de outros ruminantes, como as vacas secas, novilhas e, até, touros. 
Tabela 3. Correlações de Pearson* entre as variáveis avaliadas: área útil da propriedade (AU), área cultivada com milho para silagem (ACM), ciclo das cultivares (CC), número de plantas por metro linear (NPL), realização de controle de pragas (CP), utilização de esterco de aves (EA), tamanho do silo (TS), vacas em lactação (VL), vacas secas (VS), novilhas com até um ano (NUA), novilhas com mais de um ano (NMU), produção de leite por vaca por dia (PROD), população de plantas (POP), principais pragas incidentes (PRA), período de utilização da silagem (PUS), local de maiores perdas de silagem (MPS), produção de silagem (PS)

\begin{tabular}{|c|c|c|c|c|c|c|c|c|c|c|c|}
\hline & $\mathbf{A} \mathbf{U}$ & $\mathbf{A C M}$ & $\mathrm{CC}$ & NPL & $\mathrm{CP}$ & EA & TS & VL & VS & NMU & PROD \\
\hline POP & 0,24 & 0,43 & 0,1 & 0,75 & & & & & & & \\
\hline PRA & 0,1 & $-0,04$ & 0,07 & 0,07 & 0,85 & & & & & & \\
\hline EA & $-0,4$ & $-0,24$ & 0,85 & 0,19 & & & & & & & \\
\hline $\mathbf{T S}$ & 0,38 & 0,59 & 0,04 & $-0,01$ & $-0,06$ & $-0,92$ & & & & & \\
\hline PUS & $-0,11$ & $-0,54$ & $-0,12$ & $-0,33$ & 0,02 & & $-0,55$ & & & & \\
\hline MPS & $-0,08$ & $-0,17$ & $-0,15$ & $-0,04$ & $-0,15$ & 0,58 & $-0,22$ & & & & \\
\hline OS & 0,18 & $-0,08$ & & 0,15 & $-0,19$ & 0,92 & 0,19 & & & & \\
\hline VL & 0,49 & 0,63 & & 0,14 & $-0,02$ & $-0,17$ & 0,32 & & & & \\
\hline VS & 0,34 & 0,31 & $-0,06$ & 0,12 & 0,03 & $-0,7$ & 0,11 & 0,60 & & & \\
\hline NMU & 0,41 & 0,41 & 0,04 & 0,05 & $-0,05$ & $-0,05$ & 0,14 & 0,74 & 0,51 & & \\
\hline NUA & 0,53 & 0,53 & 0,03 & 0,09 & 0,03 & 0,19 & 0,39 & 0,74 & 0,38 & 0,61 & \\
\hline PROD & 0,28 & 0,44 & $-0,09$ & 0,01 & $-0,16$ & $-0,72$ & 0,59 & 0,35 & 0,08 & 0,18 & \\
\hline RAÇA & $-0,12$ & $-0,27$ & 0,14 & 0,06 & 0,08 & 0,72 & $-0,37$ & $-0,23$ & $-0,07$ & $-0,06$ & $-0,54$ \\
\hline
\end{tabular}

* estão sendo apresentados alguns valores, dentre eles, todas as correlações acima de $|0,50|$.

\section{CONCLUSÃO}

A região sudoeste do Paraná caracteriza-se por apresentar pequenas propriedades rurais (agricultura familiar), com 15,65 vacas em lactação e 17,2 litros de leite/dia, em média, e que armazenam a silagem em silos trincheira, em sua maioria.

As lavouras cultivadas para confecção de silagem produzem em média 40 a 50 ton ha-1 de matéria verde. Os principais híbridos utilizados para a confecção da silagem são do grupo semiduro e precoce, com sementes certificadas e tratadas.

\section{REFERÊNCIAS}

Argenta G, Silva PRF, Fleck NG, Bortolini CG, Neves R \& Agostinetto D (2001) Efeitos do manejo mecânico e químico da aveia-preta no milho em sucessão e no controle do capimpapuã. Pesquisa Agropecuária Brasileira, 36:851-860.

Balsalobre MAA, Nussio LG \& Martha Júnior GB (2001) Controle de perdas na produção de silagens de gramíneas tropicais. In: Mattos WRS (Ed.) A produção animal na visão dos brasileiros. Piracicaba, Sociedade Brasileira de Zootecnia. p.890-911.

Barioni LG, Martha Júnior GB, Ramos AKB, Veloso RF, Rodrigues DC \& Vilela L (2003). Planejamento e gestão do uso de recursos forrageiros na produção de bovinos em pastejo. In: $20^{\circ}$ Simpósio sobre Manejo da Pastagem, Piracicaba. Anais, FEALQ. p.105153

Bolsen KK \& Bolsen RE (2004) The silage triangle and important practices in managing bunker, trench, and driver-over pile silos. In: Southeast dairy herd management conference, Macon. Proceedings, Macon. p.1-7.

Bolsen KK (1996) Silage technology. In: 2a Australian Maize Conference, Queensland. Proceedings, Gatton College. p.1-30.

Bressan VGF, Muniz JN \& Rezende JB (2009) Avaliação de resultados da extensão rural pública no Estado de Minas Gerais. Revista Ceres, 56:241-248.
Corrêa CES, Pereira MN, Oliveira SG \& Ramos MH (2003) Performance of |Holstein cows fed sugarcane or corn silages of different grain textures. Scientia Agricola, 60:621-629.

Côrrea CES, Shaver RD, Pereira MN, Lauer JG, \& Kohn K (2002) Relationship between corn vitreousness and ruminal in situ starch degradability. Journal of Dairy Science, 85:3008-3012.

Dias FN (2002) Avaliação de parâmetros agronômicos e nutricionais em híbridos de milho (Zea mays L.) para silagem. Dissertação de Mestrado. Escola Superior de Agricultura "Luiz de Queiroz", São Paulo. 96p

Flaresso JÁ, Gross CD \& Almeida EX (2000) Cultivares de milho (Zea mays L.) e sorgo (Sorghum bicolor (L.) Moench.) para ensilagem no Alto Vale do Itajaí, Santa Catarina. Revista Brasileira de Zootecnia, 29:1608-1615.

Gadioli JL, Dourado Neto D, Garcia y Garcia A \& Basanta MV (2000) Temperatura do ar, rendimento de grãos de milho e caracterização fenológica associada à soma calórica. Scientia Agrícola, 57:377-383.

Holmes CW (1996) Produção de leite a baixo custo em pastagens: uma análise do sistema neozelandês. In: $2^{\circ}$ Congresso brasileiro de gado leiteiro, Piracicaba. Anais, FEALQ. p.69-95.

IBGE (2008) Pesquisa da Pecuária Municipal. Disponível em: http://www.cnpgl.embrapa.br/nova/informacoes/estatisticas/ producao/tabela0240.php Acessado em: 17 de outubro de 2009.

IBGE (2006) Censo Agropecuário 2006 - Resultados Preliminares. Disponível em: <http://www.ibge.gov.br/estadosat/ perfil.php?sigla=pr $>$. Acessado em: Abril de 2009.

IPARDES (2009) Caracterização socieconômica da atividade leiteira no Paraná: sumário executivo / Instituto Paranaense de Desenvolvimento Econômico e Social e Instituo Paranaense de Assistência Técnica e Extensão Rural. Curitiba, IPARDES. 29p.

Johnson LM, Harrison JH, Davidson D, Mahanna WC, Shinners K \& Linder D (2002) Corn silage management: effects of maturity, inoculation, and mechanical processing on pack density and aerobic stability. Journal of Dairy Science, 85:434-444.

Keplin LAS (1992) Recomendação de sorgo e milho (silagem) safra 1992/93. Encarte Técnico da Revista Batavo. CCLPL, Castro, Parana. Ano I, n.8, p.16-19. 
Kikuti ALP, Vasconcelos RCD, Marincek A \& Fonseca AH (2003) Desempenho de sementes de milho em relação à sua posição na espiga. Ciência e Agrotecnologia, 27:765-770.

Maark R (1968) Geografia Física do Estado do Paraná. Banco de desenvolvimento do Paraná, Curitiba. p.350.

Maeda S, Kurihar CH \& Fabrício AC (1997) Calagem e Adubação. In: Milho: EMBRAPA. Centro de Pesquisa agropecuária do Oeste. Informações técnicas. Dourados, p.68-85. (EMBRAPA - CPAO. Circular Técnica, 5).

Martin TN, Venturini T, Api I, Pagnocelli A \& Vieira Júnior, PA (2011) Perfil do manejo da cultura do milho no sudoeste do Paraná. Revista Ceres, 58:695-700.

Martin TN, Pavinato PS, Silva MR, Ortiz S \& Bertoncelli P (2011a) Fluxo de nutrientes em ecossistemas de produção de forragens conservadas. In: Jobim CC, Cecato U, Canto MW (Eds). Anais do IV Simpósio: Produção e utilização de forragens conservadas, Piracicaba. p.173-219.

Martin TN \& Pavinato PS (2010) Modelo determinístico para adubação nitrogenada na cultura do milho para grãos e silagem. In: Martin TN, Ziech MF, Pavinato PS, Waclawovsky AJ \& Sklarski MMSS (Eds.). Sistemas de Produção Agropecuária, Piracicaba. p.45-69.

Mello ACL \& Pedreira CGS (2004) Respostas morfológicas do capim-tanzânia (Panicum maximum Jacq. cv. Tanzânia-1) irrigado à intensidade de desfolha sob lotação rotacionada. Revista Brasileira de Zootecnia, 33:282-289.

Neumann M, Restle J, Alves Filho DC, Brondani IL, Bernardes, RALC, Souza, ANM, Kuss F (2001) Avaliação da silagem de diferentes híbridos de sorgo (Sorghum bicolor, L. Moench) por meio do desempenho de novilhos de corte confinados. Revista Brasileira de Zootecnia, 30:2099-2109.

Oliveira JS \& Martins CE (2009) Tipos de silos. Disponível em: <http://www.cileite.com.br/tecnicas/arquivos/silo.pdf > Acessado em: Abril de 2009.

Oliveira JS, Sobrinho FS, Reis FA Silva GA, Rosa Filho SN, Souza JJR, Moreira FM, Pereira JA \& Firmino WG (2007a) Adaptabilidade e estabilidade de cultivares de milho destinados à silagem em bacias leiteiras do estado de Goiás. Pesquisa Agropecuária Tropical, 1:45-50.

Oliveira JS, Souza Sobrinho F, Santiago AD, Santos DM, Gomide CA, Pereira AV, Lanes ECM, Almeida EJD \& Ramos CR (2007b) Avaliação de híbridos comerciais de milho para utilização na forma de silagem na Mesorregião do Leste Alagoano. Medicina Veterinária, 1:26-33.

Oliveira JSF, Souza Sobrinho RC, Pereira JM, Miranda VL, Banys AC, Ruggieri AV, Pereira FJS, Lédo MA \& Botrel MV (2003) Potencial de utilização de híbridos comerciais de milho para silagem na região Sudeste do Brasil. Revista Brasileira de Milho e Sorgo, 2:62-71.

Pasciullo DSC, Lopes FCF, Aroeira LJM, Morenz MJF \& Verneque RS (2008) Disponibilidade de matéria seca, composição química e consumo de forragem em pastagem de capim-elefante nas estações do ano. Arquivo Brasileiro Medicina Veterinária e Zootecnia, 60:904-910.
Pereira MN, Von Pinho RG, Bruno RGS \& Calestine GA (2004) Ruminal degradability of hard or soft texture corn grain at three maturity stages. Science Agriculture, 61:358-363.

Philippeau C, Le-Deschault-Demoredon F \& Michalet-Doreau B (1999) Relationship between ruminal starch degradation and the physical characteristics of corn grain. Journal Animal Science, 77:238-243.

Piana AT, Silva PRF, Bredemaeier C, Sangoi L, Vieira VM, Serpa MS \& Jandrey DB (2008) Densidade de plantas de milho híbrido em semeadura precoce no Rio Grande do Sul. Ciência Rural, 38:2608-2612.

Pimentel JJO, Silva JFC, Valadares Filho SC, Cecon PR \& Santos PS (1998) Efeito da suplementação protéica no valor nutritivo de silagens de milho e sorgo. Revista Brasileira Zootecnia, 27:1042-1049.

Queiroz DM, Dias GP \& Mantovani EC (2000) Agricultura de precisão na produção de grãos. In: Borém AB, Giúdice MP, Queiroz DM, Mantovani EC, Ferreira LR, Valle FXR \& Gomide RT (Eds.) Agricultura de precisão. Vicosa, Editora UFV. p.1-42.

Restle J, Pacheco OS, Alves Filho DC, Freitas AK, Neumann M, Brondani IL, Pádua JT \& Arboitte MZ (2006) Silagem de diferentes híbridos de milho para produção de novilhos superjovens. Revista Brasileira de Zootecnia, 35:2066-2076.

Rossi Junior P, Fugisawa AC, Schogor ALB \& Muraro GB (2006) Digestibilidade aparente de dois cultivares de milho, cortados em diferentes alturas, submetidos à ensilagem. Archives of Veterinary Science, 11:58-61.

Sangoi L, Lech VA, Rampazzo C \& Gracietti LC (2002) Acúmulo de matéria seca em híbridos de milho sob diferentes relações entre fonte e dreno. Pesquisa Agropecuária Brasileira, 37:259267.

Santos GT, Cavalieri FLB \& Massuda EM (2001) Alguns aspectos econômicos e de manejo na criação de novilhas leiteiras. Balde Branco. p.56-60. Disponível em: <http://www.nupel.uem.br/ novilhas02-2000.pdf>. Acessado em: Julho de 2009

SEAB/DERAL (2003) Governo do Paraná e Secretaria de Estado da Agricultura e do Abastecimento A Pecuária Paranaense em Foco.. Disponível em: <http://www.pr.gov.br/seab/aspectos/ aspectosdapecuaria141003.pdf $>$. Acessado em: Junho de 2009.

Silva AA, Ferreira FA \& Ferreira LR (2002) Biologia e controle de plantas daninhas. Viçosa, Universidade Federal de Viçosa. CDROM.

Valle CB, Jank L \& Resende RMS (2009) O melhoramento de forrageiras tropicais no Brasil. Revista Ceres, 56:460-472.

Viana PA, Cruz I, Oliveira LJ \& Corrêa-Ferreira BS (2001) Manejo de pragas em agroecossistemas sob plantio direto. Informe Agropecuário, 22:63-72.

Vilela D, Resende JC \& Assis AG (1998) Custos das perdas que ocorrem durante a produção e utilização de silagem. In: $35^{\mathrm{a}}$ Reunião Anual da Sociedade Brasileira de Zootecnia, Botucatu. Anais, SBZ. p.583-584. 